\title{
Gene expression patterns in the hippocampus during the development and aging of Glud1 (Glutamate Dehydrogenase 1) transgenic and wild type mice
}

Xinkun Wang ${ }^{1,2,3^{*}}$, Nilam D Patel ${ }^{1}$, Dongwei Hui ${ }^{1,3}$, Ranu Pal ${ }^{1,3}$, Mohamed M Hafez ${ }^{4}$, Mohamed M Sayed-Ahmed ${ }^{4}$, Abdulaziz A Al-Yahya ${ }^{4,5}$ and Elias K Michaelis ${ }^{1,2,3}$

\begin{abstract}
Background: Extraneuronal levels of the neurotransmitter glutamate in brain rise during aging. This is thought to lead to synaptic dysfunction and neuronal injury or death. To study the effects of glutamate hyperactivity in brain, we created transgenic $(\mathrm{Tg})$ mice in which the gene for glutamate dehydrogenase (Glud1) is over-expressed in neurons and in which such overexpression leads to excess synaptic release of glutamate. In this study, we analyzed whole genome expression in the hippocampus, a region important for learning and memory, of 10 day to 20 month old Glud1 and wild type (wt) mice.

Results: During development, maturation and aging, both Tg and wt exhibited decreases in the expression of genes related to neurogenesis, neuronal migration, growth, and process elongation, and increases in genes related to neuro-inflammation, voltage-gated channel activity, and regulation of synaptic transmission. Categories of genes that were differentially expressed in $\mathrm{Tg} v$ s. wt during development were: synaptic function, cytoskeleton, protein ubiquitination, and mitochondria; and, those differentially expressed during aging were: synaptic function, vesicle transport, calcium signaling, protein kinase activity, cytoskeleton, neuron projection, mitochondria, and protein ubiquitination. Overall, the effects of Glud1 overexpression on the hippocampus transcriptome were greater in the mature and aged than the young.

Conclusions: Glutamate hyperactivity caused gene expression changes in the hippocampus at all ages. Some of these changes may result in premature brain aging. The identification of these genomic expression differences is important in understanding the effects of glutamate dysregulation on neuronal function during aging or in neurodegenerative diseases.
\end{abstract}

Keywords: Brain aging, Hippocampus, Glutamate, Gene expression profile, Genome

\section{Background}

Glutamate $(\mathrm{Glu})$ is the major excitatory neurotransmitter in the mammalian central nervous system (CNS). Glutamate activation of post-synaptic receptors leads to rapid excitation of neurons as well as long-lasting effects on neuronal structure and function $[1,2]$. Among the long-

\footnotetext{
* Correspondence: xwang@ku.edu

'Higuchi Biosciences Center, University of Kansas, 2099 Constant Ave., Lawrence, KS 66047, USA

${ }^{2}$ Alzheimer's Disease Center, University of Kansas Medical Center, Kansas City, KS 66160, USA

Full list of author information is available at the end of the article
}

lasting effects of Glu on neurons are changes in synaptic excitability $[1,3,4]$, altered metabolic states and generation of reactive oxygen species in neurons [2,5-7], increases in intracellular calcium $\left(\mathrm{Ca}^{2+}\right)$ concentrations, and upon exposure to high Glu levels, neuronal injury or cell death [8-11].

There are two other important neurobiological processes that are influenced by Glu release and the activation of neuronal Glu receptors. These are the cellular events occurring during CNS development and the neuronal changes related to the aging process. Glutamate

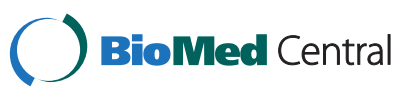


receptor activation and the influx of $\mathrm{Ca}^{2+}$ are crucial to neurogenesis and the survival of neurons during early development $[5,12,13]$, as well as to neuronal migration [14] and synaptic formation in the developing brain $[15,16]$. With regard to the aging process, neuronal, dendritic, and synaptic losses in hippocampus, subiculum, dentate gyrus, and pre-frontal cortex are subtle [17-19] and may be partially the result of a gradual rise in extracellular Glu in the aging brain [20-22]. An age-associated increase in the sensitivity of certain neurons to the cytotoxic effects of Glu [23] and a significant decrease in the dendrite levels of the microtubule-associated protein 2 (MAP2), a marker protein of dendrite structure, have been described $[24,25]$. Given the strong relationship between Glu hyperactivity and decreases in MAP2 labeling in dendrites of sensitive neurons [26-28], the MAP2 decreases in aging brain may represent a sign of increased Glu activation of receptors in susceptible neurons.

The study of neuronal responses to persistently high levels of Glu activity at synapses during development and aging requires the use of transgenic or null mutant animals that either exhibit diminished Glu re-uptake into neurons and glial cells [29-31] or have increased synaptic Glu release [32]. Null mutant mice for the high affinity glial Glu transporter genes Slc1a2 (Solute carrier family 1 member 2) and Slc1a3 exhibit high levels of extracellular Glu and suffer extensive brain damage and embryonic lethality [29-31]. Null mutants for the gene Tsc1 (Tuberous sclerosis complex-1), a gene that is closely associated with the expression and function of Glu transporters in the CNS, also have high extracellular levels of Glu and suffer from extensive neuronal damage, intractable seizures, and marked reduction in their lifespan [33]. Therefore, none of these mice would be suitable for studies of both developmental and aging effects of excess Glu synaptic activity on brain cells. On the other hand, transgenic ( $\mathrm{Tg}$ ) mice over-expressing the gene for Glu dehydrogenase 1 (Glud1), a mitochondrial matrix enzyme, only in CNS neurons have lifelong excess synaptic release of Glu, selective neuronal degeneration in vulnerable brain regions, such as the hippocampus, and a close to normal lifespan $[32,34]$.

The Glud1 Tg mouse was selected to further characterize the effects of moderate excess Glu activity on gene expression patterns in the developing, adult, middle-aged, and aging mouse brain. Whole genome transcription patterns represent an unbiased assessment of changes in genes involved in brain metabolism, neuronal excitability, neuronal structure, and the response to metabolic, oxidative and other types of stresses related to Glu hyperactivity throughout development, adulthood and aging. In the present study, we determined the gene expression patterns in $\mathrm{Tg}$ and wt mice from 10 days to 20 months of age.

\section{Results and discussion}

We performed genome wide transcriptomic analyses of the hippocampus at 5 ages, from early development at 10 days postnatal, to young adult (4.5 months), adult (9 months), middle aged (14.5 months), and old age (20 months). We included a group of very young mice, the 10 day old mice, so that we may assess the effects of the over-expressed Glud1 gene on the overall patterns of gene expression during the development of $\mathrm{Tg}$ and $\mathrm{wt}$ mice. The brain region of interest was the hippocampus.

\section{Transcriptomic similarities between Glud1 $\mathrm{Tg}$ and wt mouse hippocampus from 10 days to 20 months of age} Of the 45,037 gene probesets on the Affymetrix GeneChip arrays (Mouse Genome 430 2.0) that we employed in this study, we identified 895 genes whose expression was changing during development, maturation, and aging, and whose patterns of age-related changes were similar in both $\mathrm{Tg}$ and wt hippocampus. In this group of 895 genes, the majority were genes whose expression levels decreased with advancing age. The expression of only a relatively small fraction of the 895 genes increased gradually with age.

As shown in Figure 1, the genes that exhibited similar age-related changes in wt and $\mathrm{Tg}$ mice can be separated into two clusters. The two clusters were characterized as consisting of: 1) genes with high levels of expression in the 10-day old hippocampus but whose expression decreased with advancing age; and 2) of genes with low levels of expression in the 10-day old hippocampus but whose expression increased with advancing age. To determine which functions are associated with the genes whose expression diverged, the Gene Ontology (GO) categories significantly enriched with such genes were identified.

For the genes whose expression in hippocampus decreased with advancing age, the biological functions in the GO categories were: 1) Cytoskeleton (including actin filament and microtubule); 2) Neurogenesis; 3) Neuron projection/growth cone/axon guidance/axonogenesis; 4) Small-GTPase-mediated signal transduction; 5) Cholesterol biosynthesis; 6) Cell migration; 7) Cell cycle and cell division; and 8) Protein disulfide oxidoreductase activity and cell redox homeostasis. For the genes whose expression increased with advancing age, the significantly enriched GO categories included the following: 1) Axon and neuron projection; 2) Actin binding; 3) Small GTPase regulator activity; 4) Voltage-gated channel activity (mostly potassium); 5) Protein tyrosine kinase activity; and 6) Regulation of synaptic transmission. It was noted that two function categories, Cytoskeleton structure and function and Axon and neuron projection, contained genes that exhibited an age-associated up-regulation as well as genes whose expression was down-regulated with age. In addition to the biological functions mentioned 
Figure 1 Hierarchical clusters of genes that were expressed in Glud1 $\mathrm{Tg}$ and wt hippocampus with nearly identical patterns of change during development and aging. Upper panel (demarcated by red dashed line) includes the genes whose expression decreased with age, while the lower panel shows genes whose expression increased with age.

above, a specific biological pathway was identified as being enriched with genes whose expression increased with advancing age, the Chemokine signaling pathway.

The overall patterns of gene changes with age in both wt and Tg mouse hippocampus could be viewed as being characterized by a decline in aspects of neurogenesis, neuronal migration, cytoskeleton function, cholesterol biosynthesis, and cell redox regulation. While on the other hand, neuroinflammation, protein tyrosine kinase signaling, and voltage-gated potassium channel activity were functions that increased during the transition from newborn to adult and to old age. Increases with advancing age in the expression of genes related to neuroinflammation are consistent with previous observations of increases in the process of inflammatory response during brain aging and in neurodegenerative diseases [35].

\section{Transcriptomic differences between Glud1 $\mathrm{Tg}$ and wt mouse hippocampi across the ages from 10 days to} 20 months

The next issue that we explored was whether there were differences in age-associated gene expression in the hippocampus of wt $v s$. Tg mice. We identified 407 genes that were differentially expressed in $\mathrm{Tg} v s$. wt mouse hippocampus. We noted that the Glud1 gene was not among the differentially expressed genes. The reason for that is related to the fact that the two sets of probes for Glud1 on the GeneChip are designed to hybridize with the 3'-UTR region of the gene transcript, a region that was not present in the transgene construct that we had inserted into the mouse genome of the Glud1 $\mathrm{Tg}$ mice. Regardless of the lack of detection of excess Glud1 expression using the microarray chips, we have documented in our previous studies the insertion of the Glud1 open reading frame in the genomic DNA of the transgenic mice, as well as the over-expression of the GLUD1 protein and increased glutamate dehydrogenase activity in neurons [32], thus confirming the presence and expression of the Glud1 transgene.

The major functions of the differentially expressed genes are summarized in Table 1. Among these functions, Mitochondrial envelop and Carboxylic acid transport contain genes in the nuclear genome that code for proteins related to mitochondrial metabolism and function. These genes included: Crls1, coding for an enzyme that catalyzes the biosynthesis of di-phosphatidyl glycerol 


\begin{tabular}{|c|c|c|}
\hline Term & $P$ value & Key genes \\
\hline Ras protein signal transduction & 0.0016 & Bcl6, Brap, Eps811, Hrasls, Nras, Ptplad1, Sdcbp \\
\hline Metal ion transport (mostly for calcium and potassium) & 0.0017 & $\begin{array}{l}\text { Atp1a2, Atp1b1, Atp2c1, Cacna1h, Cacnb4, Camk2g, Itpr2, Kcnab2, } \\
\text { Kenip2, Kcnip3, Kcnk1,Kcnq2, Kent1, Sfxn1, Slc25a28, Slc38a9, Trpc4 }\end{array}$ \\
\hline Synaptic transmission & 0.013 & Atp1a2, Cacnb4, Capza2, Cpl×3, Grid2, Grm4, Lin7c, Stx1b \\
\hline Carboxylic acid transport & 0.017 & Cacnb4, Serinc1, Slc13a3, Slc1a1, Slc1a7, Slc38a9, Trpc4, \\
\hline Actin cytoskeleton organization & 0.027 & Acta1, Arhgef2, Atp2c1, Bcl6, Capza2, Dbn1, Neurl2, Nras, Sorbs1 \\
\hline $\begin{array}{l}\text { Stress-activated protein kinase signaling pathway } \\
\text { (mostly MAPK and JNK cascades) }\end{array}$ & 0.034 & Brap, Cdc42se1, Errfi1, Fgf12, Fgf2, Gm8188, Map3k7, Myd88, Ptplad1 \\
\hline Mitochondrial envelop & 0.05 & $\begin{array}{l}\text { Cds1, Cds2, Cox15, Cox4i2, Cox5a, Crls1, Cyb5b, Golph3, Nlrx1, Pi4kb } \\
\text { Ppp1cc, Sfxn1, Slc25a28, Tomm20 }\end{array}$ \\
\hline
\end{tabular}

(cardiolipin) in mitochondria; $C d s 1$ and $C d s 2$, coding for enzymes that catalyze the conversion of phosphatidic acid to CDP-diacylglycerol, a precursor to the synthesis of phosphatidyglycerol and cardiolipin; and Cox4i2, Cox 15 , and Cox5A, genes coding structural and regulatory components of the multimeric complex that forms the mitochondrial enzyme cytochrome $c$ oxidase (Table 1). Cytochrome c oxidase is a key enzyme in the electron transport system of mitochondria and one that has been reported to be decreased in terms of expression levels and activity during aging and in Alzheimer's disease [36,37]. The differential expression of these mitochondria-related genes during development, maturation, and aging were suggestive of distinctive patterns of activity between wt and Tg mouse hippocampus cells in two key mitochondrial metabolic pathways, lipid biosynthesis and oxidative phosphorylation.

In addition to the genes that code for mitochondrial proteins, another group of important genes shown in Table 1 are those of Metal ion transport, in particular, those for potassium channels. Differential expression of these genes would lead to differential regulation of neuronal excitability, sensitivity to Glu-induced neuronal damage, and neurocognitive function. Two of these genes were Kcnq2 (also known as the $\mathrm{M}$ channel) and Kcnt1, a sodium and calcium-regulated potassium channel. Mutations in these two genes are associated with early onset epileptic seizures [38,39]. A third potassium channel gene was Kcnab2, a gene that codes for the beta subunit of voltage-gated potassium channels and whose over-expression protects neurons from Glu-induced cell damage [40] while its under-expression impedes associative memory formation [41].

Of all differentially expressed genes, we identified a subgroup of eight genes which exhibited the most significant differences. These eight genes were: Akt3, Cebpg, Klhdc8a, Pex11b, Prt4, Sfxn1, Tomm20, and Ubr7. Akt3, a serine/threonine protein kinase (protein kinase $B$ ), is an important component of many signal transduction pathways. Akt3 is involved in the regulation of cell proliferation, tumorigenesis, differentiation, organismal development, metabolism, synaptic transmission, and cell junction formation [42]. Cebpg (CCAAT/enhancer binding protein gamma), a transcription factor, is associated with stress pathways including antioxidant, DNA repair, and immune responses $[43,44]$. Klhdc8a, one of the Kelch domain-containing proteins that are connected to the cytoskeleton, is related to neurite outgrowth and to the development of drug-resistant forms of gliomas $[45,46]$. Pex11b (peroxin 11b), a peroxisomal biogenesis factor, interacts with proteins involved in mitochondrial fission, is involved in lipid metabolism, myelin formation and axonal growth, and mutations in this and related Pex genes can lead to the inherited neurological and behavioral syndrome known as the Zellweger syndrome $[47,48]$. Prrt4 (proline-rich transmembrane protein 4), a gene related to Prrt2, may be associated with abnormal neurological conditions as mutations in Prrt2 lead to paroxysmal neurological states characterized by seizures and dyskinesias [49]. Sfxn1 (sideroflexin 1) is a mitochondrial inner membrane tricarboxylate and iron carrier [50]. Tomm20 (translocase of outer mitochondrial membrane 20 homolog), a component of a receptortranslocase complex in the outer mitochondrial membrane, is involved in recognition and subsequent transport into mitochondria of precursor proteins synthesized in the cytoplasm [51-53]. The differential expression across age of the two mitochondrial genes $S f x n 1$ and Tomm20 in Glud1 vs. wt mouse hippocampi might be further evidence of functional differences between $\mathrm{wt}$ and Tg mouse brain mitochondria. Finally, the differential expression patterns of $U b r 7$ (ubiquitin protein ligase E3), a member of the family of $N$-terminal ubiquitin ligases that are involved in the regulation of cellular and organismal processes such as apoptosis, neurogenesis, and learning and memory [54-56], might be an 
indication of differential patterns of folding and degradation of select proteins in $\mathrm{Tg} v s$. wt mice.

\section{Age-related periods with the highest and lowest differential gene expression between $\mathrm{Tg}$ and wt mouse hippocampi}

Among the 407 differentially expressed genes, the differences between the $\mathrm{Tg}$ and wt mouse hippocampi were not always in one direction, i.e., either over-expression or under-expression of the genes in one mouse genotype vs. the other. An analysis of the total number of genes whose expression in hippocampus differed in $\mathrm{Tg} v s$. wt mice across the five ages is shown in Figure 2. In the hippocampus of 10 day-old mice, there were relatively few differences in gene expression between Glud1 and wt mice, and most of the genes that were differentially expressed were at lower levels (down-regulation) in the $\mathrm{Tg}$ compared with the wt hippocampus. By 4.5 months of age, the number of genes whose levels of expression were lower in $\mathrm{Tg}$ than wt hippocampus had quadrupled in comparison with the 10 day old mice but, once again, only few genes were expressed at higher levels (upregulation) in $\mathrm{Tg}$ than wt mice at that age (Figure 2). This pattern reversed dramatically at 9 months of age, with a high number of genes being up-regulated in $\mathrm{Tg}$ compared with wt hippocampus. Finally, in the last two age groups-i.e. the 14.5 and 20 month old mice, the populations of differentially expressed genes were relatively small, approximately at the same levels as those at 10 days of age (Figure 2).

The high number of genes that were differentially transcribed in 4.5 and 9 month-old $\mathrm{Tg} v s$. wt mouse hippocampus might suggest that this period represented a critical stage in the maturation of the mouse hippocampus and that the over-expression of Glud1 in neurons may have had the greatest effect around this age

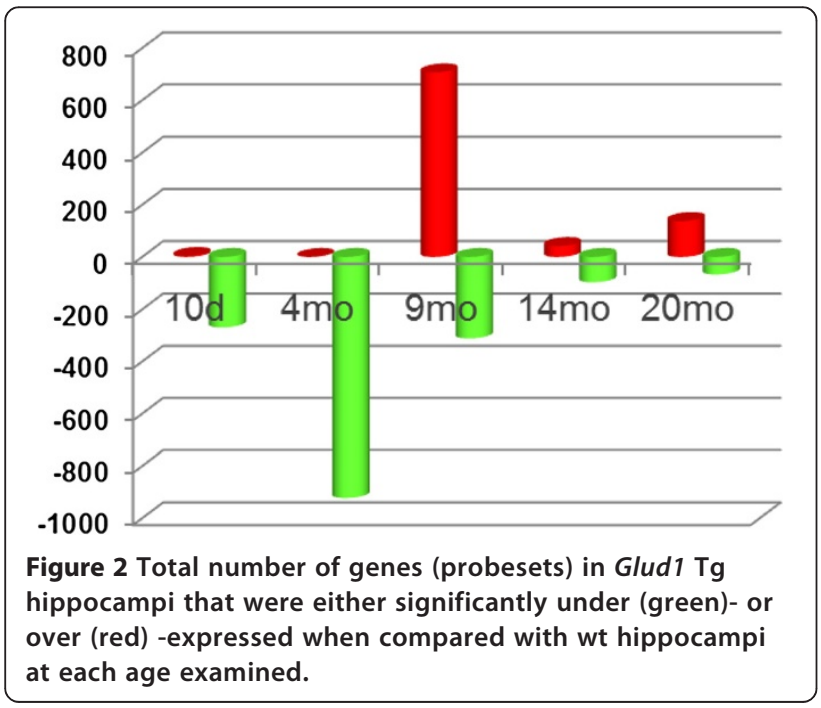

period. The GO categories enriched with genes that were differentially expressed in $\mathrm{Tg} v s$. wt mice at 4.5 and 9 months of age, revealed several key neurobiological functions that were down-regulated at 4.5 months but up-regulated at 9 months in $\mathrm{Tg} v s$. wt mouse hippocampus (Table 2). These functions were summarized as Neuronal growth and development (including neuron projection and nervous system development), Axonal pathfinding (including axonal guidance, cytoskeleton, focal and cell adhesion), and Synapse formation and signaling (including synaptic vesicle and synaptic transmission).

The group of genes related to neuronal growth and development consisted of the transcription factors Fos, Pbx1, Zeb2, and Egr2. Fos, FBJ murine osteosarcoma viral oncogene homolog, is the first immediate early gene identified to have an increased level of expression following neuronal stimulation in brain and it, together with other regulatory factors and immediate early genes, may be involved in dendrite growth and synaptic plasticity $[57,58] . P b x 1$, pre-B-cell leukemia homeobox 1 , is a homeodomain gene involved in early neuronal development, axon pathway finding, and regulation of compulsive behaviors [59-61]. Zeb2, zinc finger E-box binding homeobox 2, is a gene that is involved in early brain development and the regulation of myelination of neurons; mutations of this gene lead to microcephaly, agenesis of corpus callosum, and mental retardation [62]. Egr2, early growth response 2, is a gene involved in axonal growth and myelination and mutations in this gene are associated with congenital neurological diseases characterized by hypo-myelination and abnormal axonal growth and function in the peripheral nervous system [63]. Other differentially expressed genes related to neurite growth, pathway finding, and synapse formation included the gene Ndel1 coding for a cytoskeleton-organizing protein that controls neuron migration and outgrowth [64], the gene $\mathrm{Nrca}$ involved in neuronal cell adhesion, axonal growth and directional migration [65], and the gene Ntrk2 coding for the receptor of brain-derived neurotrophic factor (BDNF) and involved in dendritic spine growth and synapse formation [66,67]. The lower levels of expression of these genes in 4.5-month-old $\mathrm{Tg}$ as compared with wt mouse hippocampus might be an indication of delayed neuronal growth, axonal projection, and synapse formation in the $\mathrm{Tg}$ mice.

At ages past 9 months, the differences in gene expression between the Glud1 and wt mouse hippocampi were not as pronounced as at 4.5 and 9 months. Functional analyses of the GO categories significantly enriched with differentially expressed genes at these ages were indicative of some important neurobiological functions that differed between $\mathrm{Tg}$ and wt mouse hippocampi, such as cell adhesion and extracellular region, ion transport, voltage-gated channel, and synaptic activity (Table 2). 
Table 2 Bio-functions of down- or up-regulated genes in Glud1 $\mathrm{Tg}$ compared with wt hippocampus at various ages

\begin{tabular}{|c|c|c|}
\hline Age group & Down-regulated & Up-regulated \\
\hline 10 days post birth & $\begin{array}{l}\text { lon binding and transport, transmembrane transport, } \\
\text { extracellular space, neuronal development, metabolism } \\
\text { and energy generation }\end{array}$ & \\
\hline 4.5 months & $\begin{array}{l}\text { Neuron projection, axonal guidance, synaptic transmission, } \\
\text { ion binding, cytoskeleton, protein ubiquitination, intracellular } \\
\text { transport, cell adhesion, synaptic vesicle }\end{array}$ & \\
\hline 9 months & $\begin{array}{l}\text { Signal transduction, nervous system development, cell } \\
\text { adhesion, synaptic transmission, ion homeostasis }\end{array}$ & $\begin{array}{l}\text { Nervous system development, signal transduction, cytoskeleton, } \\
\text { focal adhesion, ion transport, synaptic transmission, protein folding } \\
\text { and degradation }\end{array}$ \\
\hline 14.5 months & Extracellular region, cell adhesion, and ion transport & \\
\hline 20 months & Voltage-gated channel & Synapse \\
\hline
\end{tabular}

Transcriptomic changes in the hippocampus during "developmental" and "aging" stages of life

The results of analyses of gene expression patterns outlined above were obtained by treating the data as if the age-associated changes in expression in $\mathrm{Tg}$ and wt hippocampi were part of a biological process that is expressed in a continuum from 10 days post-natal to 20 months of old age. But, we know that the immediate post-natal period up to 2-3 months of age is characterized by many changes in tissues, especially in the brain, that would be considered as developmental events. Similarly, the changes in cell and organ function with advancing age from 14.5 to 20 months would be considered part of organismal aging. For this reason, we decided to re-analyze the data on gene expression as falling into two phases in the life spectrum, a "developmental" and an "aging" stage of life. The age of 9 months appeared to represent an approximate midpoint between these two stages. Therefore, the transcriptomic data were re-analyzed by dividing them into a "developmental stage" that encompassed the period between 10 days and 9 months of age, and an "aging stage" between 9 and 20 months.

In the developmental stage, our analysis identified 217 genes which exhibited both age-dependent changes and significant expression differences between the Glud1 and wt mice. Hierarchical clustering of these genes according to changes in their expression from 10 days to 4.5 and 9 months of age is shown in Figure 3. The top group shown in Figure 3 (group I) had high levels of expression at 10 days of age and progressively lower levels at 4.5 and 9 months. The decrease in the expression of these genes in the $\mathrm{Tg}$ hippocampus at 9 months was much greater than that detected in wt mice. A GO analysis of the genes in this group indicated that the biological functions significantly enriched with these genes were RNA recognition and binding, Calcium and other metal ion binding, Protein kinase activity, Cytoskeleton, and Synapse.

The bottom group of genes shown in Figure 3 (group II), had a pattern of increasing expression with advancing age from 10 days to 9 months. These genes were also differentially expressed in $\mathrm{Tg} v s$. wt mouse hippocampus. The expression levels of these genes at 9 months of age were significantly higher in Tg compared with wt. The GO categories enriched with these genes were: Synaptic transmission, Neuron projection and cytoskeleton, Endomembrane system (including nuclear envelop and Golgi apparatus), Metal ion binding and channel activity, Protein catabolic process, Cell adhesion, Plasma membrane, Mitochondrion, and Regulation of apoptosis. The expression changes for these genes suggested that during the developmental stage, the hippocampus of the Glud1 mice differed from that of the wt in terms of important neuronal structural and functional aspects, such as neuronal projection and neurite growth, protein degradation, mitochondrial function, and metal ion binding and transport. At the age of 9 months, the cells of the hippocampus in the $\mathrm{Tg}$ mice had exceeded in the expression of most of these genes the levels observed in the wt hippocampus.

A much greater number of probesets $(1,257)$ than those that were differentially expressed in the "developmental stage" showed differential expression between Glud1 vs. wt hippocampus during the "aging stage", i.e., from 9 to 20 months of age (Figure 4). Only few of these genes had a continuously increasing or decreasing pattern of expression from 9 to 20 months of age. Most genes fell into one of two major groups: those whose expression increased between 9 and 14.5 months and then decreased at 20 months of age (marked as Group I in Figure 4), and those whose expression decreased between 9 and 14.5 months and then increased again at 20 months (Group III in the figure). Genes in Group I were further separated into two subgroups based on their relative expression levels in $\mathrm{Tg} v s$. wt at the start of this aging stage (marked as Subgroups I-1 and I-2 in Figure 4). Genes in Subgroup I-1 were expressed at higher levels in Tg than wt at 9 months of age, and the GO categories significantly associated with these genes included Cytoskeleton, Golgi apparatus, Vesicle-mediated transport, Calcium ion binding, and Protein transport. Since three of these GO categories are related to intracellular transport 
Figure 3 Hierarchical clustering of genes that were differentially expressed in the Tg vs. wt hippocampi during the "developmental stage" (10 day, 4.5 and 9 month old). The clusters are further

subdivided into 3 gene expression patterns that were similar in $\mathrm{Tg}$ and wt hippocampi even though there were differences in ov: those decreasing in expression levels with advancing age and with the expression in the $\mathrm{Tg}$ mice at 9 months being lower than the wt (panel I); those with increasing expression with advancing age and with the Tg expression levels being higher than the wt at 9 months (panel II); and those with a mixed pattern of age-related change in expression (middle panel).

processes, the expression pattern of these genes might represent possible adaptations of cells in the $\mathrm{Tg}$ mouse hippocampus that would lead to increased growth or elongation of processes. Genes in Subgroup I-2 were expressed at lower levels in $\mathrm{Tg}$ than wt at 9 months, and the GO categories associated with these genes included Regulation of transcription, Metal ion binding, and Protein kinase activity, i.e., suggestive of changes in intracellular signaling and regulation of protein synthesis in the Glud1 Tg mouse hippocampus.

Group III genes, i.e., those whose expression levels decreased from 9 to 14.5 months and then partially rebounded at 20 months, were similarly divided into two subgroups. The genes in Subgroup III-2 (Figure 4) were expressed at higher levels in $\mathrm{Tg}$ than wt at 9 months of age, and the GO categories enriched with genes in this subgroup were RNA binding, Protein kinase activity and ATP binding, GTPase regulator activity, Microtubule cytoskeleton, Actin skeleton, and Neuron projection. This grouping showed, once again, that intracellular transport and neurite projection processes, i.e., microtubule and actin cytoskeleton, were at higher levels in Tg than wt hippocampi at 9 months and appeared to increase again, but moderately, at 20 months. Genes in the other subgroup (III-1) were expressed at lower levels in Tg than wt at 9 months, and the categorical GO functions included Ribosome, Purine metabolism, Mitochondrion, RNA binding, Proteolysis, Protein transport, and Calmodulin binding. Thus, protein synthesis and metabolism, as well as mitochondrial activity, appeared to be at lower levels in $\mathrm{Tg}$ than wt hippocampus at 9 mos, and increased only moderately at 20 months. Among the mitochondriarelated genes in this group was Crls1, the gene that codes for cardiolipin synthase. Cardiolipin is almost exclusively expressed in mitochondria and is present in the inner mitochondrial membrane where it enhances the activity of the electron transport system and ATP synthesis [68]. Cardiolipin is susceptible to oxidation and loss of activity with advancing age [69], therefore, the higher expression of Crls1 in wt compared with that in Tg hippocampus may afford greater retention of normal mitochondrial function in wt than Tg mice during the aging process. The differential levels of genes related to mitochondrial function in wt 
Figure 4 Hierarchical clustering of genes that were differentially expressed in the Tg vs. wt hippocampi during the "aging stage" $(9,14.5$, and 20 month old). The clusters are further subdivided into differing gene expression patterns across age of both $\mathrm{Tg}$ and wt mice. A further subdivision of the clusters was made based on whether the gene expression levels for the Tg hippocampi were higher at 9 months than those for the wt (see text for full description).

vs. Tg hippocampus, appeared to be a recurring theme at different ages.

The gene categories described above were populated with genes that were transcribed either at high or intermediate levels at the start of the aging process. But, there was another group of the genes shown in Figure 4 whose expression was at low levels at 9 months but increased at 14.5 and 20 months in both Tg and wt mouse hippocampi (Group II). This group of genes could also be divided into two subgroups, one whose expression was consistently higher in $\mathrm{Tg}$ than wt hippocampus at 9 months (Subgroup II-1), and the other lower in Tg than wt (Subgroup II-2). For those genes in Subgroup II-1, the biological functions represented were those of Protein ubiquitination and degradation, Cytoskeleton and cell projection, mRNA transport, Protein transport, Chaperone activity, Endoplasmic reticulum, Mitochondrion, and Regulation of apoptosis. Therefore, in addition to cytoskeleton, transport, and neurite growth that were characteristic of genes enriched in the 9 month-old hippocampus of Tg mice, cell and ER stress were also enriched in this subgroup, specifically, protein ubiquitination, chaperone activity, ER, protein degradation, and regulation of apoptosis. Some of these biological functions will be analyzed further in a subsequent section. The genes in Subgroup II-2 were related to Synapse and synaptic vesicle, RNA binding, Cell surface receptor linked signal transduction, ER, Phosphatase activity, Regulation of transcription, and Protein transport.

As summarized in Figure 5 on the effect of Glud1 transgene overexpression on mouse hippocampal aging, neurite projection and growth, protein ubiquitination and degradation, cytoskeleton and intracellular transport, cellular and ER stress, and mitochondrial activity were the major functional categories associated with genes whose expression levels were up-regulated in the $\mathrm{Tg}$ mice. Some genes related to mitochondrial activity were also down-regulated in the aging stage, as was true also with respect to genes related to synaptic function.

Combining the results from all ages, encompassing both the developmental and aging stages, allowed us to identify five categories of cell functions that were consistently and significantly differentially regulated in $\mathrm{Tg}$ vs. wt hippocampus. The first three were Cytoskeleton, Intracellular transport, and Neurite projection and growth. Aspects of differential expression of cytoskeleton and 


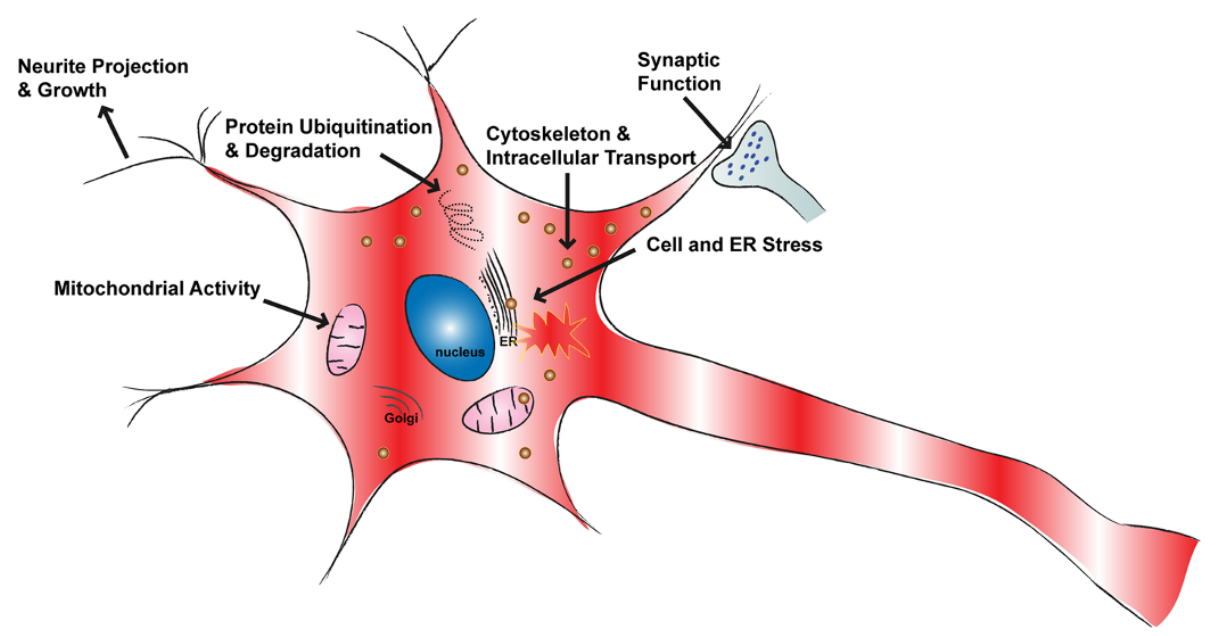

Figure 5 Major functions of genes differentially regulated in Glud1 Tg vs. wt mice during the aging stage. Most functions, including Neurite projection and growth, Protein ubiquitination and degradation, Cytoskeleton and intracellular transport, Cell and ER stress, and Mitochondrial activity, were up-regulated in the Glud1 Tg mice.

neurite projection genes in the hippocampus of $\mathrm{Tg}$ as compared with those of wt mice were described previously for a single age group, the 9 month old group [70] and will be analyzed further in subsequent studies focused on the function of axonal transport in the brain and hippocampus (P. Lee, R. Pal, X. Wang, I-Y. Choi, and E. K. Michaelis, unpublished observations). The other two key functions were Protein ubiquitination and degradation, and Mitochondrial structure and function, which are analyzed next.

\section{Differential gene expression of protein ubiquitination and degradation in Tg vs. wt hippocampus}

Increases in protein ubiquitination and degradation are a characteristic of cellular responses to stress, occur in the CNS during aging and in age-associated neurodegenerative diseases, and are collectively referred to as altered proteostasis $[71,72]$. In the present study, a number of protein ubiquitination-related genes showed significant differential expression between the Glud1 and wt mouse hippocampus, with the Tg hippocampus exhibiting higher levels of expression than the wt across several age groups (Figure 6). Among the genes related to protein ubiquitination were two E2 ubiquitin conjugating enzymes, Ube2q1 (ubiquitin-conjugating enzyme E2q) and Hip2 (or Ube2k), huntingtin interacting protein 2 (or ubiquitin conjugating enzyme E2k). Ube2q1 is associated with the endocytic pathway and the proteasomal degradation of proteins [73], while Hip2 is involved in ubiquitination and aggregation of polyglutamine-containing proteins such as the protein huntingtin in Huntington's disease [74]. In addition to the two E2 ubiquitin-conjugating enzymes, three genes, $\mathrm{Ubr} 7$, Ube3a and Itch, coding for E3 ubiquitin-protein ligases were also differentially expressed in $\mathrm{Tg} v s$. wt mice, especially at the age of 9 months (Figure 6). In terms of the role of these genes in CNS function, $U b r 7$ is one of fifty genes whose mutations are linked to autosomal recessive intellectual disabilities [75], while suppression of the expression of $U b e 3 a$ in the hippocampus and cerebellum of children leads to the clinical syndrome known as Angelman's syndrome characterized by seizures and mental and developmental disabilities [76]. Itch codes for an E3 ligase that is associated with endothelin A and is part of the endosomal degradation pathway in cells of the nervous system [77].

As pointed out by others [78,79], the expression of these genes may enhance axonal growth, dendritic spine elongation and synapse formation during early development or later in life, thus determining both the structure and function of synapses through ubiquitination and proteasomal degradation of key proteins. Included among the proteins whose placement and cycling at synapses are the Glu receptor proteins in glutamatergic synapses. Such changes in the rates of placement and removal of macromolecules from synapses may alter synaptic transmission and thus have a protective role in chronically stimulated synapses, such as those that exist in the hippocampus of the Glud1 Tg mice.

Several additional genes related to ubiquitination and protein degradation, were over-expressed in the $\mathrm{Tg}$ as compared with the wt hippocampus, including Cul4a (ubiquitination complex E3 ligase component), a gene which when over-expressed offers protection against the damage induced by hypoxia and ischemia [80,81]; Fbxw1b (F-box and WD-containing 1b) which codes for a component of a ubiquitination complex that includes 


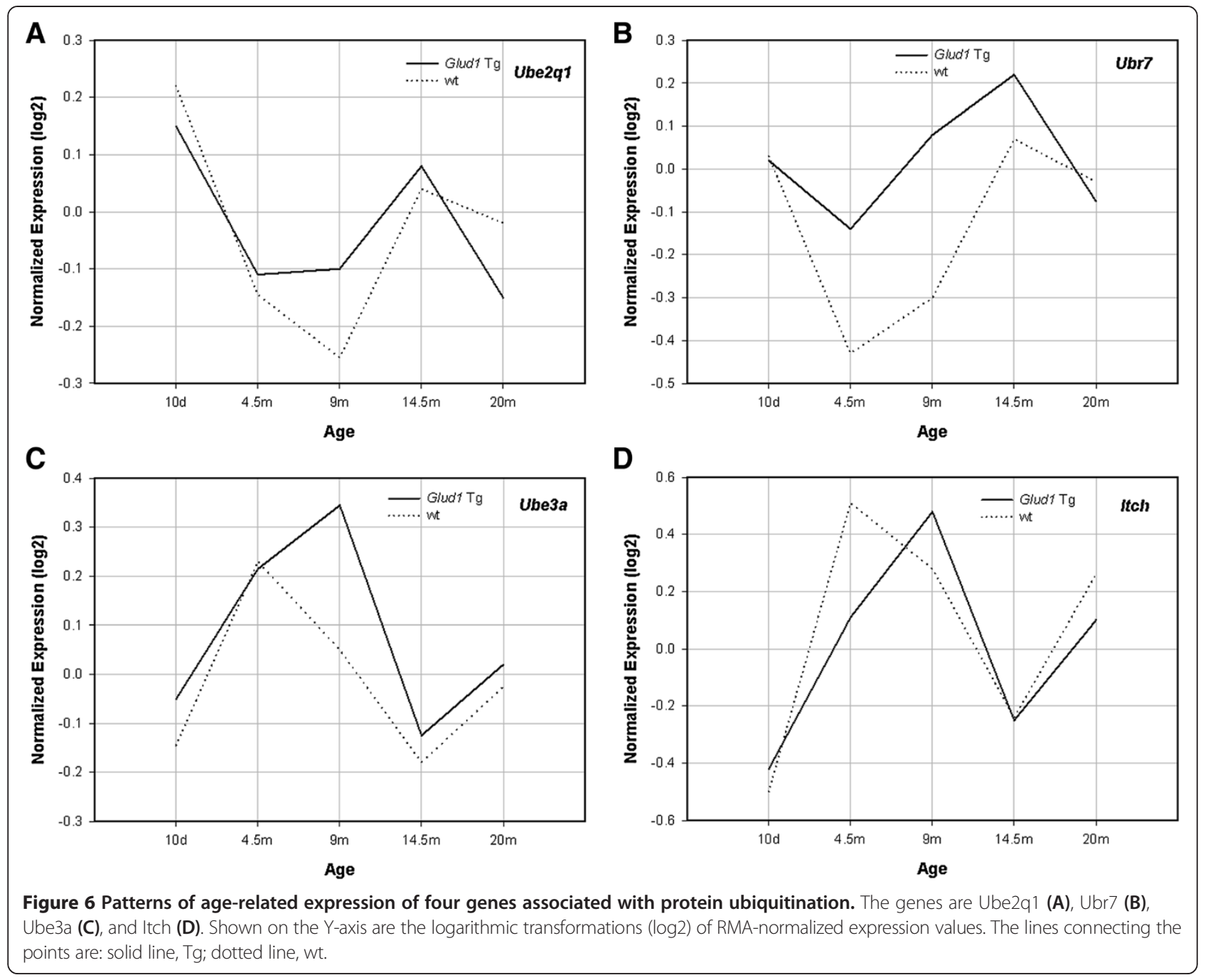

CUL4 and which leads to proteasomal degradation of targeted proteins [82]; Rab40c, a member of an ubiquitin E3 ligase complex and one that is highly expressed in oligodendrocytes and may be involved in myelin formation or repair [83]; and, Usp 7, 19, and 20 (ubiquitin specific proteases 7, 19, and 20) and Psmd14 (proteasome $26 \mathrm{~S}$ subunit non-ATPase 14), a proteasome component involved in the degradation of proteins. Thus, the expression patterns of the genes for the ubiquitin conjugating enzymes, the ubiquitin ligases, and the ubiquitin-specific proteases enumerated above were suggestive of increased endosomal transport, protein ubiquitination, and proteasomal degradation of ubiquitinated proteins in Glud1 $\mathrm{Tg}$ mouse hippocampus. Such differential expression might lead to altered dynamics at synapses, altered proteostasis, and possibly higher levels of ER stress in the Tg mice. Yet, even such up-regulation of genes of the ubiquitin proteasome system (UPS) may not be sufficient in meeting the increased demands of protein processing needed to maintain normal function in the Glud1 $\mathrm{Tg}$ mice. This might explain why neurons in the hippocampus of Glud1 $\mathrm{Tg}$ mice, especially in the susceptible CA1 region of the hippocampus, exhibit increasing amounts of ubiquitinated protein aggregates after 14 to 16 months of age [32].

It should be noted, however, that not all genes that code for ubiquitinating enzyme proteins were expressed at higher levels in $\mathrm{Tg}$ mice throughout development or aging. An example of a gene that was expressed at higher levels in wt mice during early development as well as in the aged mice is Birc6 (data not shown), a gene that codes for an E2 ubiquitin-conjugating enzyme containing a UBCc domain and a BIR (baculoviral inhibition of apoptosis protein repeat) domain. Pro-apoptotic proteins are ubiquitinated by BIRC6 and subsequently degraded, and that leads to the suppression of apoptosis of cells $[84,85]$. In the early developmental phase (10 days to 4.5 months), Birc6 expression was significantly higher in wt than Tg hippocampus. Such a deficiency in BIRC6 in Tg mice might produce a pro-apoptotic effect during development and maturation of the hippocampus and 
might be correlated with some of the neuronal losses in the hippocampus of Glud1 mice [32].

\section{Differential expression of mitochondria-related genes in Tg vs. wt hippocampus}

As described above, genes related to mitochondrial structure and function were also differentially expressed in Glud1 Tg vs. wt mouse hippocampi. Mitochondria play a crucial role in energy metabolism, oxidative stress, apoptosis, calcium regulation, and aging-related neuronal injury. The up-regulation of expression of some of the genes related to mitochondrial function in the $\mathrm{Tg}$ mouse hippocampus in young adult to middle aged periods, might be an indication of cellular attempts to sustain normal metabolic activity in the face of increased demand for bioenergetic output. Tomm20, Cds2, Mars2, and $M t c h 2$ were among the mitochondrial genes identified as exhibiting distinct patterns of differential expression across ages in $\mathrm{Tg} v \boldsymbol{s}$. wt mouse hippocampi, especially between the ages of 4.5 and 14.5 months (Figure 7). The expression of Tomm 20 increased steadily from 10 days to 14.5 months of age in $\mathrm{Tg}$ mice, whereas the pattern of expression in wt mouse hippocampus exhibited both peaks and valleys over the same period of maturation. The expression of Cds2 and Mars2 peaked in Glud1 mouse hippocampi at 9 months of age and plateaued or moderately decreased after that (Figure 7). The expression of the same two genes in the wt mouse hippocampus lagged behind that in the Tg. The importance of Cds2 in mitochondrial and brain function was described in a preceding section. The gene Mars 2 codes for a methionyl-tRNA synthetase, a mitochondrial matrix enzyme whose malfunction causes a neurodegenerative phenotype in flies and a recessive form of ataxia in humans [86].

The last in this group of mitochondria-related genes that were differentially expressed in $\mathrm{Tg} v s$. wt mouse hippocampi was Mtch2 (mitochondrial carrier homolog 2) which exhibited a different pattern of expression in both $\mathrm{Tg}$ and wt hippocampi than those of Tomm20, Cds2, and Mars2 but the overall levels of expression of Mtch2 were, again, higher in $\mathrm{Tg}$ than wt mice (Figure 7). The protein encoded by this gene is an inner mitochondrial membrane protein presumed to function as a transport carrier and to cause mitochondrial membrane depolarization and activation of the cascade of events that lead to mitochondriaassociated apoptosis [87]. Although the function of Mtch2 has been described for liver mitochondria, Mtch2 is also highly expressed in the mouse hippocampus [88]. Based on the pro-apoptotic function of Mtch2, the chronically higher expression of this gene in adult and older Tg mice compared with wt mice, coupled with the lower expression level in Tg than wt mouse hippocampi of the antiapoptotic gene Birc6 (described above), might enhance the probability of age-associated neuronal cell losses in the hippocampus of the Glud1 mice.

\section{PCR Confirmation of patterns of expression of genes in Tg and wt hippocampus}

The expression in mouse brain, and especially in the hippocampus, of many of the genes described above was confirmed through reports in the scientific literature and through searches in the Allen Brain Atlas (http://www. brain-map.org/). For most of the genes described in this paper, such confirmation was obtained. In order to confirm a few of the gene expression patterns that we observed using the GeneChips, we performed parallel quantitative PCR analyses of select genes across the age spectrum. The results of the combined PCR and microarray analyses are shown for three such genes in Figure 8. Although the magnitude of differences between $\mathrm{Tg}$ and wt hippocampi in different age groups detected by PCR did not exactly match the values obtained by microarray analyses, the overall patterns of the PCR-measured gene expression in these limited number of samples appeared to reproduce those observed by microarray analyses.

\section{Conclusions}

A global assessment of the changes in the categories of Neuronal development, Nerve process extension, excitability, Synapse formation, Intracellular signaling, Metabolic regulation, Ion transport, and Protein homeostasis, was obtained in the present study by analyzing gene expression changes in the hippocampus of Glud1 $\mathrm{Tg}$ and wt mice from 10 days of life to the old age of 20 months. To our knowledge, this is the first study to explore whole genome transcriptomic changes across the life-span of mice and, specifically, the life-span of two genotypes of C57BL/6 mice, the Glud1 Tg and wt mice. We could not find literature references or brain maps that present the patterns of gene expression in mouse brain, or mouse hippocampus in particular, across the ages from 10 days to 20 months. A few gene expression patterns have been traced up to 56 days of mouse post-natal life by the Allen Brain Atlas (http://www.brain-map.org/). However, because of the limited span of ages examined in this brain mapping effort, these studies do not provide sufficient information about changes in gene expression beyond two months of age.

Among the many changes in gene expression levels during development, maturation, and aging that are described in the present study, a few stand out as being important to neuronal development, function, and survival in the hippocampus. With regard to the aging process, and regardless of the genotype of the mice, there was an age-associated significant decrease in the expression of genes related to Neurogenesis, Neuronal 


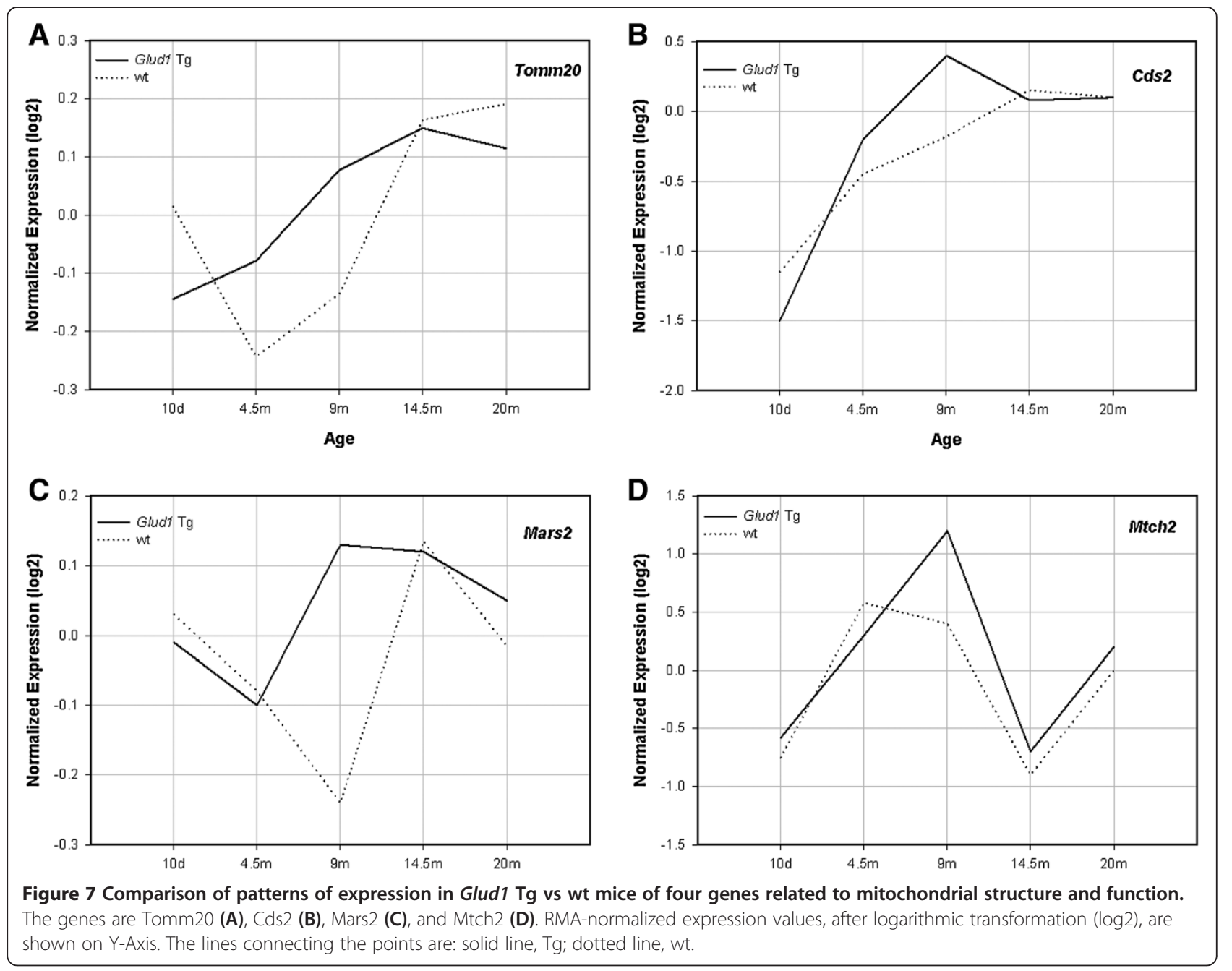

migration, Neuronal growth and process elongation, and an increase in genes related to Neuro-inflammation, Voltage-gated channel activity, and Regulation of synaptic transmission. As pointed out in other sections of this paper and in previous publications [35,89], the upregulation of inflammatory response genes appears to be a common characteristic of aging in the CNS. The upregulation of voltage-gated channels, primarily potassium channels, is a novel observation. Changes in ion channel expression would be an important component in the control of neuronal function and viability. Increased neuronal excitation due to Glu hyperactivity is known to lead to intracellular and intra-mitochondrial calcium accumulation and, potentially, cell death [2], thus decreases in the excitability that results from increased expression of certain potassium channels would protect neurons from Glu-induced hyper-excitability.

Among the major differences between the Glud1 $\mathrm{Tg}$ and wt mice during development and aging was the differential expression of genes related to Protein homeostasis-i.e., genes associated with protein ubiquitination and proteasomal degradation. As was pointed out in other sections in this paper, increases in protein ubiquitination, protein endocytosis, and protein degradation may influence synapse formation and synaptic function during development, and the same processes may affect neuronal excitability and synaptic activity in the CNS during aging. Increased protein ubiquitination and degradation are also a characteristic of cellular stress response and the increased expression of genes related to ubiquitin conjugation during the aging process was previously described for hippocampus nerve cells [90]. In our studies, we observed not only up-regulation of genes for ubiquitin conjugation, but also genes for protein degradation, and, interestingly, these increases in gene expression during the aging process were not of the same magnitude in $\mathrm{Tg}$ as in wt mice. These transcriptomic observations indicate a higher stress level, accelerated aging, and possibly increased attempts to control synaptic function and excitability in the Glud1 Tg mice as compared with wt mice.

The regulation of mitochondrial function across age as determined by gene changes that alter mitochondrial 

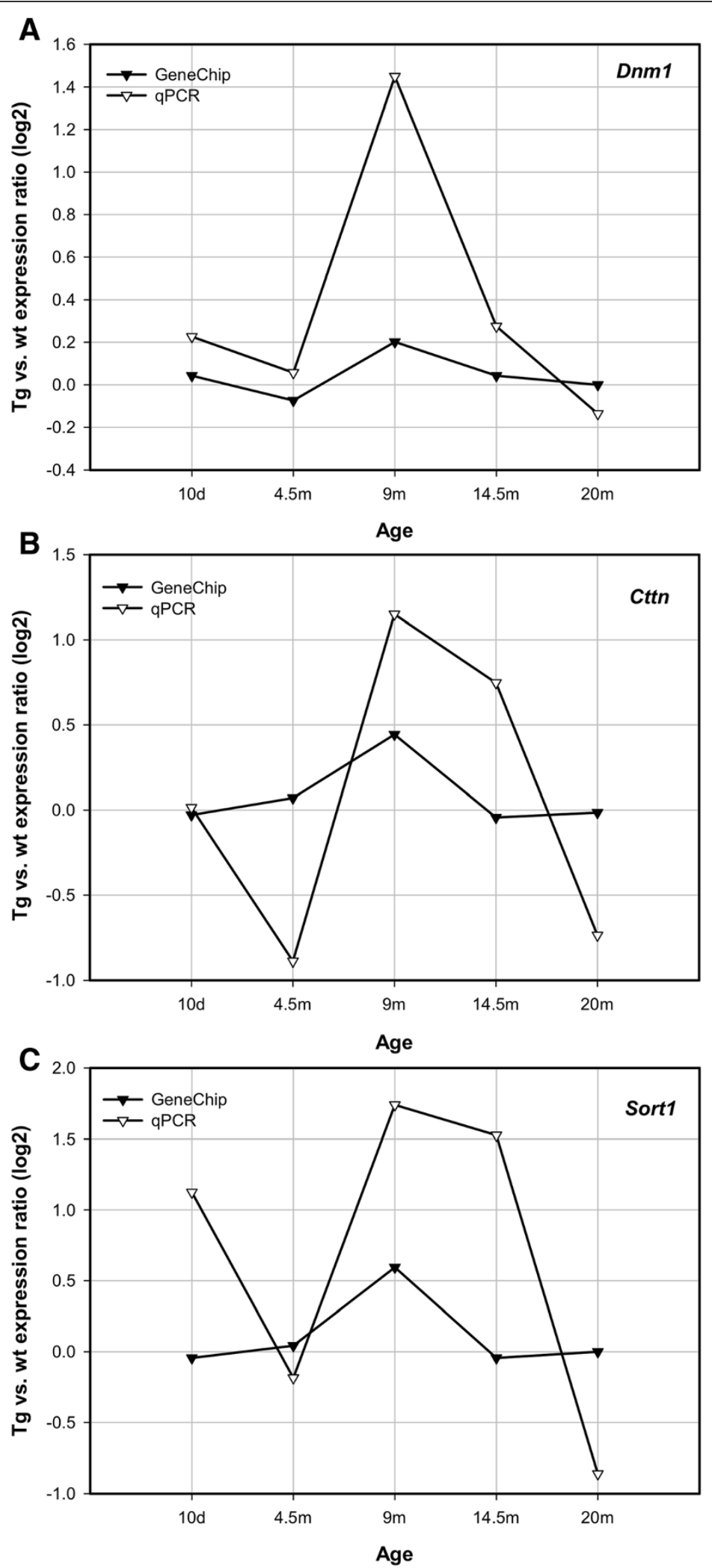

Figure 8 Comparison of the ratio of Tg/wt expression across age of three significant genes as assessed by GeneChip and qPCR

methods. The genes are Dnm1 (A), Cttn (B), and Sort1 (C). Shown on the Y-axis are the ratios Tg/wt of the logarithmic transformations (log2) of RMA-normalized expression values. 
lipid synthesis, cytochrome c oxidation, and protein or solute transport, might be some of the most important aspects of the aging process revealed by the results of our studies. Several studies have previously identified changes in gene expression with advancing age as fitting within the category of mitochondrial dysfunction and oxidative stress $[69,91,92]$. And as has been pointed out before, altered mitochondrial oxidative phosphorylation and the generation of reactive oxygen species represent the type of dysfunction that leads to cell and organ senescence [93]. Of particular interest in our studies were the differences in genes associated with mitochondrial protein transport, such as TOMM20 and MTCH2, iron transport, enzyme regulation, e.g. cytochrome oxidase subunits, and mitochondrial lipid metabolism. We have commented already on the significance of the differential expression of some of these genes in wt $v s$. Tg mouse hippocampi. It is worth pointing out again the relevance in terms of mitochondrial function of the increased expression of TOMM20 in the Tg mice. TOMM20 is an important component of the pathway that maintains normal mitochondrial function and whose loss of function could contribute to the accumulation of dysfunctional mitochondria [94]. The increased expression of TOMM 20 in the Glud1 Tg mouse hippocampus during development and adulthood may be a direct response to the increased need for GLUD1 protein translocation from the cytoplasm into the mitochondrial matrix. Yet, when one considers the increases in Tomm20 expression in combination with the other differential changes in mitochondrial gene expression in Glud1 $\mathrm{Tg}$ vs. wt mice, it would appear that these differential expression characteristics reflect adaptive or compensatory changes made by brain cells to overcome the increased stress exerted by altered metabolic states in the Glud1 $\mathrm{Tg}$ mice.

\section{Methods}

\section{Experimental animals}

The procedure for generating the $\mathrm{Tg}$ mice was described in detail previously [32]. Age-matched wt mice of the same genetic background (C57BL/6) were used as the controls. All animals were housed in a 12 hour light/ dark cycle with food and water ad libitum. All animal procedures were performed in accordance with guidelines established by the University of Kansas IACUC. Male Glud1 $\mathrm{Tg}$ and wt mice at five different ages were used: 10 day old, 4.5 month, 9 month, 14.5 month, and 20 month old. A total of $3 \mathrm{Tg}$ and 3 wt mice were used for transcriptomic studies of each age group.

\section{RNA extraction and microarray data generation}

The mice used for the transcriptomic studies were anesthetized under $\mathrm{CO}_{2}$ anesthesia, the hippocampi dissected out from the brains, flash frozen in liquid nitrogen, and stored at $-80^{\circ} \mathrm{C}$ prior to total RNA extraction. Total RNA samples were extracted from the dissected hippocampi using the Qiagen RNeasy Mini Kit (Qiagen, Valencia, CA, USA). To prepare targets for subsequent GeneChip hybridization, One-Cycle cDNA Synthesis Kit from Affymetrix (Santa Clara, CA, USA) was used according to the manufacturer's instructions. The Affymetrix GeneChip Mouse Genome 4302.0 arrays designed to interrogate expression of over 39,000 mouse gene transcripts, were used for the hybridization. Subsequent washing and staining steps were performed on a GeneChip Fluidics 450 Station and the chips were scanned on a GeneChip Scanner 3000 (Affymetrix). Instrument control and data collection were carried out using GeneChip Operating Software (GCOS, ver 1.1.1). In order to minimize experimental variability, all steps in tissue dissection, RNA isolation and microarray operation were performed by a single investigator. The quality and quantity of the original RNA samples and of the cRNA probes generated for array hybridization were determined with an Agilent 2100 Bioanalyzer (Agilent Technologies, Palo Alto, CA, USA), and a NanoDrop ND1000 Spectrophotometer (Thermo Scientific, Wilmington, DE, USA). The microarray data generated from all chips met the quality control criteria set by Affymetrix, including low background and noise, positive detection of QC probesets such as bioB, percentage of genes called present in normal range (generally between 40-60\%), similar scaling factors across all chips, and Acceptable 3'/5' ratios. All microarray data were deposited into the NCBI GEO (Gene Expression Omnibus) database with accession number GSE48911.

\section{Transcriptomic data analysis}

The GeneChip transcriptomic data collected across the five age points of $\mathrm{Tg}$ and wt mouse hippocampus were analyzed: a) at each individual age; b) across the developmental stage (the first three age groups); c) across the aging process (the last three age groups); and d) across all five age points. For each analysis, the GeneChip CEL data were first normalized by the Robust Multiarray Average (RMA) algorithm [95]. Prior to each identification of genes showing significant differential expression patterns between $\mathrm{Tg}$ and $\mathrm{wt}$, probesets that were detected to be non-expressed, i.e., those with absence calls in all analyzed samples, were filtered out and excluded from further analyses. In addition, probesets that were designed solely for the purpose of chip quality control (monitoring hybridization target preparation and array hybridization), i.e., those with the ID prefix AFFX, were also filtered out. These filtering steps were employed in order to reduce the number of comparisons in subsequent analyses and thus reduce the FDR.

To identify differentially expressed genes at each individual age point, SAM (Significance Analysis of 
Microarrays), a supervised learning software for genomic expression data mining [96], was first used with the threshold for calling differential gene expression set at fold change $\geq 1.3$ and FDR $\leq 1 \%$. This was followed by Cyber-T analysis [97] in order to confirm expression patterns of differential genes identified by SAM, using the criterion of Bayesian $P$ value $\leq 0.05$. To identify genes showing both age-dependent change and differential expression between $\mathrm{Tg}$ and wt, a software package called EDGE (http://www.genomine.org/edge/) was used [98]. Gene hierarchical clustering was performed using the software GeneSpring GX (Agilent Technologies). Gene Ontology (GO) and Biological Pathway analyses were conducted with DAVID (http://david.abcc.ncifcrf.gov/) [99].

\section{Competing interests}

The authors declare that they have no competing interests.

\section{Authors' contributions}

XW and EKM conceived of the study and drafted the manuscript. XW also carried out the RNA extraction, GeneChip data generation, bioinformatics data analyses, and participated in real-time quantitative PCR confirmation of the GeneChip data. EKM was also involved in the interpretation of the transcriptomic data and coordinated the study. NDP, MMH, MSS and AAA conducted the real-time quantitative PCR analysis. DH maintained the Glud1 Tg and wt mice. RP carried out characterization of the animals. All authors read and approved the final manuscript.

\section{Acknowledgements}

This work was supported by grants AG12993 and AG035982 from the National Institute on Aging, grants AA11419 and AA04732 from the National Institute on Alcohol Abuse and Alcoholism, the Kansas Technology Corporation, the Miller, Hedwig and Wilbur Fund, the University of Kansas Research Development Fund, and the government of the Kingdom of Saudi Arabia and the King Saud University.

\section{Author details}

'Higuchi Biosciences Center, University of Kansas, 2099 Constant Ave Lawrence, KS 66047, USA. ${ }^{2}$ Alzheimer's Disease Center, University of Kansas Medical Center, Kansas City, KS 66160, USA. ${ }^{3}$ Department of Pharmacology and Toxicology, University of Kansas, Lawrence, KS, USA. ${ }^{4}$ Department of Pharmacology and Toxicology, School of Pharmacy, King Saud University, Riyadh, Saudi Arabia. ${ }^{5}$ Ibn Sina National College, Jeddah, Saudi Arabia.

Received: 17 July 2013 Accepted: 24 February 2014

Published: 4 March 2014

\section{References}

1. Cotman CW, Monaghan DT, Ganong AH: Excitatory amino acid neurotransmission: NMDA receptors and Hebb-type synaptic plasticity. Annu Rev Neurosci 1988, 11:61-80.

2. Michaelis EK: Molecular biology of glutamate receptors in the central nervous system and their role in excitotoxicity, oxidative stress and aging. Prog Neurobio/ 1998, 54(4):369-415.

3. Ito M: Long-term depression. Annu Rev Neurosci 1989, 12:85-102.

4. Bear MF, Abraham WC: Long-term depression in hippocampus. Annu Rev Neurosci 1996, 19:437-462.

5. Mattson MP: Glutamate and Neurotrophic Factors in Neuronal Plasticity and Disease. Ann N Y Acad Sci 2008, 1144(1):97-112.

6. Cheng A, Hou Y, Mattson MP: Mitochondria and neuroplasticity. ASN neuro 2010, 2(5):e00045.

7. Dawson VL, Dawson TM, London ED, Bredt DS, Snyder SH: Nitric oxide mediates glutamate neurotoxicity in primary cortical cultures. Proc Natl Acad Sci U S A 1991, 88(14):6368-6371.

8. Aarts M, lihara K, Wei WL, Xiong ZG, Arundine M, Cerwinski W, MacDonald JF, Tymianski M: A key role for TRPM7 channels in anoxic neuronal death Cell 2003, 115(7):863-877.
9. Lafon-Cazal M, Culcasi M, Gaven F, Pietri S, Bockaert J: Nitric oxide, superoxide and peroxynitrite: putative mediators of NMDA-induced cell death in cerebellar granule cells. Neuropharmacology 1993, 32(11):1259-1266.

10. Meldrum B, Evans M, Griffiths T, Simon R: Ischaemic brain damage: the role of excitatory activity and of calcium entry. Br J Anaesth 1985, 57(1):44-46.

11. Arundine M, Tymianski M: Molecular mechanisms of calcium-dependent neurodegeneration in excitotoxicity. Cell Calcium 2003, 34(4-5):325-337.

12. Burgoyne RD, Cambray-Deakin MA: The cellular neurobiology of neuronal development: the cerebellar granule cell. Brain Res 1988, 472(1):77-101.

13. Balazs $\mathrm{R}$, Jorgensen OS, Hack N: N-methyl-D-aspartate promotes the survival of cerebellar granule cells in culture. Neuroscience 1988, 27(2):437-451.

14. Komuro $H$, Rakic P: Modulation of neuronal migration by NMDA receptors. Science 1993, 260(5104):95-97.

15. Mattson MP, Dou P, Kater SB: Outgrowth-regulating actions of glutamate in isolated hippocampal pyramidal neurons. J Neurosci 1988, 8(6):2087-2100.

16. Bhatt DH, Zhang S, Gan WB: Dendritic spine dynamics. Annu Rev Physiol 2009, 71:261-282.

17. Burke SN, Barnes CA: Neural plasticity in the ageing brain. Nat Rev Neurosci 2006, 7(1):30-40

18. Miller DB, O'Callaghan JP: Aging, stress and the hippocampus. Ageing Res Rev 2005, 4(2):123-140

19. Hof PR, Morrison JH: The aging brain: morphomolecular senescence of cortical circuits. Trends Neurosci 2004, 27(10):607-613.

20. Zoia C, Cogliati T, Tagliabue E, Cavaletti G, Sala G, Galimberti G, Rivolta I, Rossi V, Frattola L, Ferrarese C: Glutamate transporters in platelets: EAAT1 decrease in aging and in Alzheimer's disease. Neurobiol Aging 2004 25(2):149-157.

21. Nickell J, Pomerleau F, Allen J, Gerhardt GA: Age-related changes in the dynamics of potassium-evoked L-glutamate release in the striatum of Fischer 344 rats. J Neural Transm 2005, 112(1):87-96.

22. Zoia CP, Tagliabue E, Isella V, Begni B, Fumagalli L, Brighina L, Appollonio I, Racchi M, Ferrarese C: Fibroblast glutamate transport in aging and in $A D$ : correlations with disease severity. Neurobiol Aging 2005, 26(6):825-832.

23. Brewer GJ: Neuronal plasticity and stressor toxicity during aging Exp Gerontol 2000, 35(9-10):1165-1183.

24. Chauhan N, Siegel G: Age-dependent organotypic expression of microtubule-associated proteins (MAP1, MAP2, and MAP5) in rat brain. Neurochem Res 1997, 22(6):713-719

25. Di Stefano G, Casoli T, Fattoretti P, Gracciotti N, Solazzi M, Bertoni-Freddari C: Distribution of map2 in hippocampus and cerebellum of young and old rats by quantitative immunohistochemistry. J Histochem Cytochem 2001, 49(8):1065-1066.

26. Arias C, Arrieta I, Massieu L, Tapia R: Neuronal damage and MAP2 changes induced by the glutamate transport inhibitor dihydrokainate and by kainate in rat hippocampus in vivo. Exp Brain Res 1997, 116(3):467-476.

27. Hoskinson MM, Yanagawa Y, Obata K, Shuttleworth CW: Calcium-dependent NMDA-induced dendritic injury and MAP2 loss in acute hippocampal slices. Neurosci 2007, 145(1):66-79.

28. Buddle M, Eberhardt E, Ciminello LH, Levin T, Wing R, DiPasquale K, Raley-Susman KM: Microtubule-associated protein 2 (MAP2) associates with the NMDA receptor and is spatially redistributed within rat hippocampal neurons after oxygen-glucose deprivation. Brain Res 2003, 978(1-2):38-50

29. Matsugami TR, Tanemura K, Mieda M, Nakatomi R, Yamada K, Kondo T, Ogawa M, Obata K, Watanabe M, Hashikawa T, Tanaka K: From the Cover: Indispensability of the glutamate transporters GLAST and GLT1 to brain development. Proc Natl Acad Sci U S A 2006, 103(32):12161-12166.

30. Rothstein JD, Dykes-Hoberg M, Pardo CA, Bristol LA, Jin L, Kund RW, Kanai Y, Hediger MA, Wang Y, Schielke JP, Welty DF: Knockout of glutamate transporters reveals a major role for astroglial transport in excitotoxicity and clearance of glutamate. Neuron 1996, 16(3):675-686.

31. Tanaka K, Watase K, Manabe T, Yamada K, Watanabe M, Takahashi K, Iwama H, Nishikawa T, Ichihara N, Kikuchi T, Okuyama S, Kawashima N, Hori S, Takimoto M, Wada K: Epilepsy and exacerbation of brain injury in mice lacking the glutamate transporter GLT-1. Science 1997, 276(5319):1699-1702.

32. Bao X, Pal R, Hascup KN, Wang Y, Wang WT, Xu W, Hui D, Agbas A, Wang X, Michaelis ML, Choi IY, Belousov AB, Gerhardt GA, Michaelis EK: Transgenic expression of Glud1 (glutamate dehydrogenase 1) in neurons: in vivo model of enhanced glutamate release, altered synaptic plasticity, and selective neuronal vulnerability. J Neurosci 2009, 29(44):13929-13944. 
33. Zeng LH, Ouyang $Y$, Gazit V, Cirrito JR, Jansen LA, Ess KC, Yamada KA, Wozniak DF, Holtzman DM, Gutmann DH, Wong M: Abnormal glutamate homeostasis and impaired synaptic plasticity and learning in a mouse model of tuberous sclerosis complex. Neurobiol Dis 2007, 28(2):184-196.

34. Michaelis EK, Wang X, Pal R, Bao X, Hascup KN, Wang Y, Wang WT, Hui D, Agbas A, Choi IY, Belousov A, Gerhardt GA: Neuronal Glud1 (glutamate dehydrogenase 1) over-expressing mice: increased glutamate formation and synaptic release, loss of synaptic activity, and adaptive changes in genomic expression. Neurochem Int 2011, 59(4):473-481.

35. Pizza V, Agresta A, D'Acunto CW, Festa M, Capasso A: Neuroinflamm-aging and neurodegenerative diseases: an overview. CNS Neurol Disord Drug Targets 2011, 10(5):621-634.

36. Swerdlow RH: Mitochondria and cell bioenergetics: increasingly recognized components and a possible etiologic cause of Alzheimer's disease. Antioxid Redox Signal 2012, 16(12):1434-1455.

37. Cottrell DA, Blakely EL, Johnson MA, Ince PG, Borthwick GM, Turnbull DM: Cytochrome c oxidase deficient cells accumulate in the hippocampus and choroid plexus with age. Neurobiol Aging 2001, 22(2):265-272.

38. Miraglia Del Giudice E, Coppola G, Scuccimarra G, Cirillo G, Bellini G, Pascotto A: Benign familial neonatal convulsions (BFNC) resulting from mutation of the KCNQ2 voltage sensor. Eur J Hum Genet 2000 8(12):994-997.

39. Kingwell K: Genetics: Mutations in potassium channel KCNT1[mdash]a novel driver of epilepsy pathogenesis. Nat Rev Neurol 2012, 8(12):658.

40. Ben-Ari S, Ofek K, Barbash S, Meiri H, Kovalev E, Greenberg DS, Soreq H, Shoham S: Similar cation channels mediate protection from cerebellar exitotoxicity by exercise and inheritance. J Cell Mol Med 2012, 16(3):555-568.

41. Perkowski JJ, Murphy GG: Deletion of the Mouse Homolog of KCNAB2, a Gene Linked to Monosomy 1p36, Results in Associative Memory Impairments and Amygdala Hyperexcitability. J Neurosci 2011, 31(1):46-54.

42. Hers I, Vincent EE, Tavare JM: Akt signalling in health and disease. Cell Signal 2011, 23(10):1515-1527.

43. Kaisho T, Tsutsui H, Tanaka T, Tsujimura T, Takeda K, Kawai T, Yoshida N, Nakanishi K, Akira S: Impairment of natural killer cytotoxic activity and interferon gamma production in CCAAT/enhancer binding protein gamma-deficient mice. J Exp Med 1999, 190(11):1573-1582.

44. Mullins DN, Crawford EL, Khuder SA, Hernandez DA, Yoon Y, Willey JC: CEBPG transcription factor correlates with antioxidant and DNA repair genes in normal bronchial epithelial cells but not in individuals with bronchogenic carcinoma. BMC Cancer 2005, 5:141.

45. Seng S, Avraham HK, Jiang S, Venkatesh S, Avraham S: KLHL1/MRP2 mediates neurite outgrowth in a glycogen synthase kinase 3beta-dependent manner. Mol Cell Biol 2006, 26(22):8371-8384

46. Mukasa A, Wykosky J, Ligon KL, Chin L, Cavenee WK, Furnari F: Mutant EGFR is required for maintenance of glioma growth in vivo, and its ablation leads to escape from receptor dependence. Proc Natl Acad Sci 2010, 107(6):2616-2621.

47. Ahlemeyer B, Gottwald M, Baumgart-Vogt E: Deletion of a single allele of the Pex11 $\beta$ gene is sufficient to cause oxidative stress, delayed differentiation and neuronal death in mouse brain. Dis Model Mech 2012, 5(1):125-140.

48. Schrader M, Reuber BE, Morrell JC, Jimenez-Sanchez G, Obie C, Stroh TA, Valle D, Schroer TA, Gould SJ: Expression of PEX11beta mediates peroxisome proliferation in the absence of extracellular stimuli. J Biol Chem 1998, 273(45):29607-29614.

49. Heron SE, Dibbens LM: Role of PRRT2 in common paroxysmal neurological disorders: a gene with remarkable pleiotropy. J Med Genet 2013, 50(3):133-139.

50. Miyake S, Yamashita T, Taniguchi M, Tamatani M, Sato K, Tohyama M: Identification and characterization of a novel mitochondria tricarboxylate carrier. Biochem Biophys Res Commun 2002, 295(2):463-468.

51. Yano M, Kanazawa M, Terada K, Takeya M, Hoogenraad N, Mori M: Functional analysis of human mitochondrial receptor Tom20 for protein import into mitochondria. J Biol Chem 1998, 273(41):26844-26851.

52. Hachiya N, Mihara K, Suda K, Horst M, Schatz G, Lithgow T: Reconstitution of the initial steps of mitochondrial protein import. Nature 1995 376(6542):705-709.

53. Schleiff E, Shore GC, Goping IS: Interactions of the Human Mitochondrial Protein Import Receptor, hTom20, with Precursor Proteins in Vitro Reveal
Pleiotropic Specificities and Different Receptor Domain Requirements. J Biol Chem 1997, 272(28):17784-17789.

54. An JY, Seo JW, Tasaki T, Lee MJ, Varshavsky A, Kwon YT: Impaired neurogenesis and cardiovascular development in mice lacking the E3 ubiquitin ligases UBR1 and UBR2 of the N-end rule pathway. Proc Natl Acad Sci U S A 2006, 103(16):6212-6217.

55. Kwon YT, Balogh SA, Davydov IV, Kashina AS, Yoon JK, Xie Y, Gaur A, Hyde L, Denenberg $\mathrm{VH}$, Varshavsky A: Altered activity, social behavior, and spatial memory in mice lacking the NTAN1p amidase and the asparagine branch of the N-end rule pathway. Mol Cell Biol 2000, 20(11):4135-4148.

56. Balogh SA, Kwon YT, Denenberg VH: Varying intertrial interval reveals temporally defined memory deficits and enhancements in NTAN1-deficient mice. Learn Mem 2000, 7(5):279-286.

57. Lyons MR, West AE: Mechanisms of specificity in neuronal activity-regulated gene transcription. Prog Neurobiol 2011, 94(3):259-295.

58. Sugo N, Oshiro H, Takemura M, Kobayashi T, Kohno Y, Uesaka N, Song W-J, Yamamoto N: Nucleocytoplasmic translocation of HDAC9 regulates gene expression and dendritic growth in developing cortical neurons. Eur J Neurosci 2010, 31(9):1521-1532.

59. Redmond L, Hockfield S, Morabito MA: The Divergent Homeobox Gene PBX1 Is Expressed in the Postnatal Subventricular Zone and Interneurons of the Olfactory Bulb. J Neurosci 1996, 16(9):2972-2982.

60. Sgado $P$, Ferretti $E$, Grbec D, Bozzi $Y$, Simon HH: The atypical homeoprotein Pbx1a participates in the axonal pathfinding of mesencephalic dopaminergic neurons. Neural Dev 2012, 7:24.

61. Nestadt G, Wang Y, Grados MA, Riddle MA, Greenberg BD, Knowles JA, Fyer AJ, McCracken JT, Rauch SL, Murphy DL, Rasmussen SA, Cullen B, Piacentini J, Geller D, Pauls D, Bienvenu OJ, Chen Y, Liang KY, Goes FS, Maher B, Pulver AE Shugart YY, Valle D, Samuels JF, Chang YC: Homeobox genes in obsessive-compulsive disorder. Am J Med Genet B Neuropsychiatr Genet 2012, 159B(1):53-60

62. Heinritz W, Zweier C, Froster UG, Strenge S, Kujat A, Syrbe S, Rauch A, Schuster $V$ : A missense mutation in the ZFHX1B gene associated with an atypical Mowat-Wilson syndrome phenotype. Am J Med Genet A 2006, 140A(11):1223-1227.

63. Warner LE, Mancias P, Butler IJ, McDonald CM, Keppen L, Koob KG, Lupski JR: Mutations in the early growth response 2 (EGR2) gene are associated with hereditary myelinopathies. Nat Genet 1998, 18(4):382-384.

64. Toba S, Hirotsune S: A unique role of dynein and nud family proteins in corticogenesis. Neuropathology 2012, 32(4):432-439.

65. Sakurai T: The role of NrCAM in neural development and disordersBeyond a simple glue in the brain. Mol Cell Neurosci 2012, 49(3):351-363.

66. Gottmann $\mathrm{K}$, Mittmann T, Lessmann V: BDNF signaling in the formation, maturation and plasticity of glutamatergic and GABAergic synapses. Exp Brain Res 2009, 199(3-4):203-234.

67. Singh B, Henneberger C, Betances D, Arevalo MA, Rodríguez-Tébar A, Meier JC, Grantyn R: Altered Balance of Glutamatergic/GABAergic Synaptic Input and Associated Changes in Dendrite Morphology after BDNF Expression in BDNF-Deficient Hippocampal Neurons. J Neurosci 2006, 26(27):7189-7200.

68. Schlame M, Rua D, Greenberg ML: The biosynthesis and functional role of cardiolipin. Prog Lipid Res 2000, 39(3):257-288.

69. Petrosillo G, Matera M, Casanova G, Ruggiero FM, Paradies G: Mitochondrial dysfunction in rat brain with aging: Involvement of complex I, reactive oxygen species and cardiolipin. Neurochem Int 2008, 53(5):126-131.

70. Wang X, Bao X, Pal R, Agbas A, Michaelis EK: Transcriptomic responses in mouse brain exposed to chronic excess of the neurotransmitter glutamate. BMC Genomics 2010, 11:360.

71. Saxena S, Cabuy E, Caroni P: A role for motoneuron subtype-selective ER stress in disease manifestations of FALS mice. Nat Neurosci 2009, 12(5):627-636.

72. Morimoto Rl: Proteotoxic stress and inducible chaperone networks in neurodegenerative disease and aging. Genes Dev 2008, 22(11):1427-1438.

73. Gorbea C, Pratt G, Ustrell V, Bell R, Sahasrabudhe S, Hughes RE, Rechsteiner M: A Protein Interaction Network for Ecm 29 Links the 26 S Proteasome to Molecular Motors and Endosomal Components. J Biol Chem 2010, 285(41):31616-31633.

74. de Pril R, Fischer DF, Roos RAC, van Leeuwen FW: Ubiquitin-conjugating enzyme E2-25 K increases aggregate formation and cell death in polyglutamine diseases. Mol Cell Neurosci 2007, 34(1):10-19.

75. Foster DB, Ho AS, Rucker J, Garlid AO, Chen L, Sidor A, Garlid KD, O'Rourke B: Mitochondrial ROMK channel is a molecular component of mitoK(ATP). Circ Res 2012, 111(4):446-454. 
76. Wallace Michael L, Burette Alain C, Weinberg Richard J, Philpot Benjamin D: Maternal Loss of Ube3a Produces an Excitatory/Inhibitory Imbalance through Neuron Type-Specific Synaptic Defects. Neuron 2012, 74(5):793-800

77. Rines AK, Bayeva M, Ardehali H: A new pROM king for the mitoK(ATP) dance: ROMK takes the lead. Circ Res 2012, 111(4):392-393.

78. Patrick GN: Synapse formation and plasticity: recent insights from the perspective of the ubiquitin proteasome system. Curr Opin Neurobiol 2006, 16(1):90-94.

79. Hamilton AM, Zito K: Breaking It Down: The Ubiquitin Proteasome System in Neuronal Morphogenesis. Neural Plast 2013, 2013:10.

80. Xu GP, Dave KR, Vivero R, Schmidt-Kastner R, Sick TJ, Perez-Pinzon MA: Improvement in neuronal survival after ischemic preconditioning in hippocampal slice cultures. Brain Res 2002, 952(2):153-158.

81. Sarabi AS, Shen H, Wang Y, Hoffer BJ, Backman CM: Gene expression patterns in mouse cortical penumbra after focal ischemic brain injury and reperfusion. J Neurosci Res 2008, 86(13):2912-2924.

82. Wojtovich AP, Williams DM, Karcz MK, Lopes CM, Gray DA, Nehrke KW, Brookes PS: A novel mitochondrial K(ATP) channel assay. Circ Res 2010 106(7):1190-1196.

83. Kaufman RJ, Back SH, Song B, Han J, Hassler J: The unfolded protein response is required to maintain the integrity of the endoplasmic reticulum, prevent oxidative stress and preserve differentiation in beta-cells. Diabetes Obes Metab 2010, 12(Suppl 2):99-107.

84. Qiu XB, Markant SL, Yuan J, Goldberg AL: Nrdp1-mediated degradation of the gigantic IAP, BRUCE, is a novel pathway for triggering apoptosis. EMBO J 2004, 23(4):800-810.

85. Chen Z, Naito M, Hori S, Mashima T, Yamori T, Tsuruo T: A human IAP-family gene, apollon, expressed in human brain cancer cells. Biochem Biophys Res Commun 1999, 264(3):847-854.

86. Bayat $\mathrm{V}$, Thiffault I, Jaiswal M, Tetreault M, Donti T, Sasarman F, Bernard G, Demers-Lamarche J, Dicaire MJ, Mathieu J, Vanasse M, Bouchard JP, Rioux MF, Lourenco CM, Li Z, Haueter C, Shoubridge EA, Graham BH, Brais B, Bellen $\mathrm{HJ}$ : Mutations in the mitochondrial methionyl-tRNA synthetase cause a neurodegenerative phenotype in flies and a recessive ataxia (ARSAL) in humans. PLoS Biol 2012, 10(3):e1001288.

87. Katz C, Zaltsman-Amir Y, Mostizky Y, Kollet N, Gross A, Friedler A: Molecular basis of the interaction between proapoptotic truncated BID (tBID) protein and mitochondrial carrier homologue $2(\mathrm{MTCH} 2)$ protein: key players in mitochondrial death pathway. J Biol Chem 2012 287(18):15016-15023.

88. Kis B, Nagy K, Snipes JA, Rajapakse NC, Horiguchi T, Grover GJ, Busija DW: The mitochondrial KATP channel opener BMS-191095 induces neuronal preconditioning. Neuroreport 2004, 15(2):345-349.

89. Pizza V, Agresta A, D'Acunto CW, Festa M, Capasso A: Neuroinflammation and ageing: current theories and an overview of the data. Rev Recent Clin Trials 2011, 6(3):189-203.

90. Zeier Z, Madorsky I, Xu Y, Ogle WO, Notterpek L, Foster TC: Gene expression in the hippocampus: regionally specific effects of aging and caloric restriction. Mech Ageing Dev 2011, 132(1-2):8-19.

91. Navarro A, Sánchez Del Pino MJ, Gómez C, Peralta JL, Boveris A: Behavioral dysfunction, brain oxidative stress, and impaired mitochondrial electron transfer in aging mice. Am J Physiol Regul Integr Comp Physiol 2002, 282(4):R985-R992.

92. Boveris $A$, Navarro $A$ : Brain mitochondrial dysfunction in aging. IUBMB Life 2008, 60(5):308-314

93. Trifunovic A, Larsson NG: Mitochondrial dysfunction as a cause of ageing. J Intern Med 2008, 263(2):167-178

94. Van Laar VS, Berman SB: The interplay of neuronal mitochondria dynamics and bioenergetics: implications for Parkinson's disease. Neurobiol Dis 2013, 51:43-55.

95. Bolstad BM, Irizarry RA, Astrand M, Speed TP: A comparison of normalization methods for high density oligonucleotide array data based on variance and bias. Bioinformatics 2003, 19(2):185-193.

96. Tusher VG, Tibshirani R, Chu G: Significance analysis of microarrays applied to the ionizing radiation response. Proc Natl Acad Sci U S A 2001 98(9):5116-5121.
97. Baldi P, Long AD: A Bayesian framework for the analysis of microarray expression data: regularized $\mathrm{t}$-test and statistical inferences of gene changes. Bioinformatics 2001, 17(6):509-519.

98. Leek JT, Monsen E, Dabney AR, Storey JD: EDGE: extraction and analysis of differential gene expression. Bioinformatics 2006, 22(4):507-508.

99. da Huang W, Sherman BT, Lempicki RA: Systematic and integrative analysis of large gene lists using DAVID bioinformatics resources. Nat Protoc 2009, 4(1):44-57.

doi:10.1186/1471-2202-15-37

Cite this article as: Wang et al: Gene expression patterns in the hippocampus during the development and aging of Glud1 (Glutamate Dehydrogenase 1) transgenic and wild type mice. BMC Neuroscience 2014 15:37

\section{Submit your next manuscript to BioMed Central and take full advantage of:}

- Convenient online submission

- Thorough peer review

- No space constraints or color figure charges

- Immediate publication on acceptance

- Inclusion in PubMed, CAS, Scopus and Google Scholar

- Research which is freely available for redistribution

Submit your manuscript at www.biomedcentral.com/submit
C Biomed Central 